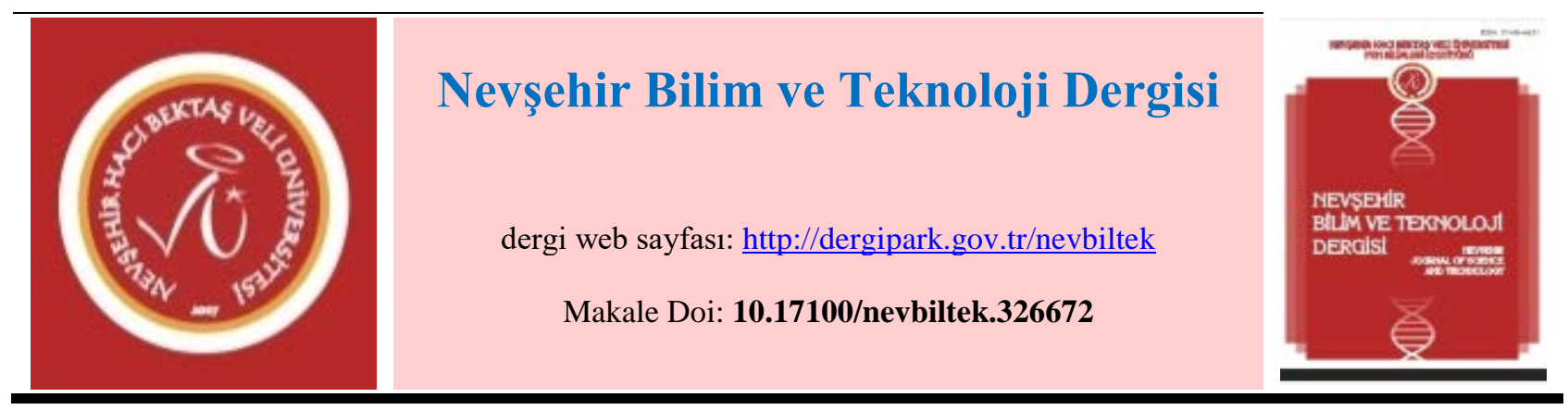

\title{
Annelerin Çocuk Besleme Uygulamaları ve Çocukların Yemek Yeme Davranışları
}

\author{
Yahya Özdoğan ${ }^{1 *}$, Serap Balaban², Aslı Uçar ${ }^{3}$ \\ ${ }^{1}$ Ankara Yıldırım Beyazıt Üniversitesi, Sağllk Bilimleri Fakültesi, Beslenme ve Diyetetik Bölümü, Ankara \\ 2,3, Ankara Üniversitesi, Să̆lık Bilimleri Fakültesi, Beslenme ve Diyetetik Bölümü, Ankara
}

Öz

Bu çalışmada, okul öncesi dönem çocuğu olan annelerin çocuklarını besleme uygulamaları ile çocukların yemek yeme davranışlarının değerlendirilmesi amaçlanmıştır. Çalışma Ankara ilinde 2-6 yaş grubu çocuğu olan 255 anne ile gerçekleştirilmiştir. Annelerin çocuk besleme uygulamaları CFQ (Child Feeding Questionnaire), çocukların yeme davranışı CEBQ (Child Eating Behavior Questionnaire) ölçeği kullanılarak belirlenmiştir. Araştırma sonucunda elde edilen veriler, SPSS istatistik programından yararlanılarak değerlendirilmiştir. Çocukların \%47.8'i kız, \%52.2'si erkektir. Çocukların çoğunluğu (\%78.8) 3 yaşın üzerindedir. Annelerin \%50.2'si çocuklarının doğru besinleri tercih etmesinden her zaman kendini sorumlu tutmakta ve çocuklarının yediği şekerli (\%78.4), abur cubur (\%75.3) ve yağ içeriği yüksek besinleri (\%78.4) kontrol etmektedirler. Anneler bazen çocuklarının yemek yemeyi sevdiğini (\%34.9), tabağında yemek bıraktığını (\%49.0), yeni yiyeceklerin tadına bakmaktan zevk aldığını (\%38.0) düşünürken, \%42.4’ü yeni yiyecekleri reddettiğini, \%35.3'ü bazen yemekle mutlu etmenin zor olduğunu düşünmektedir. Her iki ölçekte de alt boyut toplam puanları incelendiğinde cinsiyetler arasında anlamlı farklılık bulunamamıştır $(\mathrm{p}>0.05)$. Annelerin yeme baskısı ile çocukların besinden keyif alma $(\mathrm{r}=-.230$; $\mathrm{p}<0.01)$ davranışı negatif yönlü, besin seçiciliği $(\mathrm{r}=-.196 ; \mathrm{p}<0.01)$, tokluk heveslisi olma ( $\mathrm{r}=.363 ; \mathrm{p}<0.05)$, yavaş yeme davranışı $(\mathrm{r}=.243$; $\mathrm{p}<0.01)$ pozitif yönlü korelasyon göstermektedir. Annelerin yeme baskısı ile kısıtlama ( $\mathrm{r}=.306$; $\mathrm{p}<0.01)$ ve çocuk ağırlı̆ı̆ hakkındaki ilgi davranışı $(\mathrm{r}=.383$; $\mathrm{p}<0.05)$ pozitif yönlü korelasyon göstermektedir. Bu çalışma sonucunda annelerin çocuklarının beslenmesinde baskıcı bir tutum izledikleri görülmüştür.

Anahtar Kelimeler: Çocuk, çocuk besleme, yeme davranışı, yeme baskısı, kısıtlama

\section{Mothers's Child Feeding Practices and Children's Eating Behaviors}

\section{Abstract}

In this study, it was aimed to evaluate the feeding practices of mothers and children's eating behavior who have pre-school children and childs'eating behavior. The study was conducted with 255 mothers of 2-6 age group in Ankara. Child feeding practices were determined with CFQ (Child Feeding Questionnaire) and child eating behavior were determined with CEBQ (Child Eating Behavior Questionnaire). The data has been evaluated appropriate SPSS statistichal methods. $47.8 \%$ of the children were female, while $52.2 \%$ were male. The majority of children (78.8\%) were older than 3 years. $50.2 \%$ of mothers feels that she was always responsible for their childrens' choices of food and they feel the need to keep under control to their childrens' sugar (78.4\%), junk food (75.3\%) and fat-rich foods (78.4\%) consumption. Mother thinks that their children likes eating (34.9\%), does not finish their food (49.0\%), likes to taste different foods (38.0\%), while $42.4 \%$ of them reject new food, $35.3 \%$ of them thinks that sometimes it is hard to make happy of their children with food. There were no significant difference between the gender when the subscale total scores were examined in both scales ( $p>0.05)$. Mother's pressure of eating and children's nutritional $(r=-.230 ; p<0.01)$ enjoyment correlate negatively, but food selection $(r=-.196$; $p<0.01)$, satiety responsiveness $(r=.363 ; p<0.05)$, slowness in eating behavior of children $(r=.243 ; p<0.01)$ and mother's pressure of eating correlate positively.

${ }^{{ }^{*} 1}$ e-mail: yozdogan@ybu.edu.tr 
Nevşehir Bilim ve Teknoloji Dergisi (2018), 7(1) 1-13

It has been determined that mothers' pressure of eating $(\mathrm{r}=.306$; $\mathrm{p}<0.01)$ and children weight $(\mathrm{r}=.383$; $\mathrm{p}<0.05)$ correlate positively. As a result of this study, it has been observed that the mothers have a repressive attitude in the feeding of their children.

Keywords: Child, child feeding, eating behaviour, pressure to eat, restriction

\section{Giriş}

Okul öncesi, doğumdan 6 yaşa kadar olan süreyi kapsayan çocuğun duygusal, sosyal, zihinsel ve fiziksel yönden gelişimini sağladığı her tür uyarı ve aktiviteyi içine alan ve yetişkinlik için temel oluşturan birçok alışkanlığın oluştuğu bir dönemdir. $\mathrm{Bu}$ nedenle bütün gelişim dönemlerini desteklemesinin yanı sıra, sağlıklı beslenme alışkanlıklarının kazandırılmasında da önemlidir [1]. Çocuk gelişmenin en hızlı olduğu bu dönemde büyüme ve gelişmenin devamı ve hastalıklara karşı direncin sağlanması için yeterli ve dengeli beslenmelidir. Böylece, erişkin dönemde genetik özelliklerine uygun bir vücut yapısına erişebilecek ve yaşamını sağlıklı devam ettirebilmesi mümkün olacaktır [2 ve 3].

Beslenme alışkanlıkları açısından okul öncesi dönem, çocuğun hem yeni besinlerle tanıştığı hem alıştığı bir dönemi kapsar. Bu dönemde hoşlanılan ve hoşlanılmayan besinler belirlenmekte ve kazanılan olumlu beslenme alışkanlıkları ile ileri yaşlarda dejeneratif hastalıklara yakalanma riski azalmaktadır [1 ve 4].

Yeme davranışı çocuğun bireysel yapısı, sağlı̆̆ı, çocuk ve ailenin duygusal durumu, ailenin çocuk gelişimi hakkındaki bilgisi, aile çocuk ilişkisi, ailenin içinde bulunduğu sosyo-ekonomik durum ve kültürden etkilenerek gelişmekte ve şekillenmektedir. Okul öncesi dönemde büyümenin yavaşlamasıyla beraber iştah daha önceki dönemlere kıyasla azalmakta, besin alımı düzensizleşmekte ve çocuğun bir öğünde yiyebileceği miktarın kontrolü güçleşmektedir. $\mathrm{Bu}$ dönemde aileler çocuğun beslenmesi konusunda sıklıkla endişe duymaya başlamaktadırlar. Bu da ailelerin çocuk üzerinde baskı kurmasına yol açmaktadır. Çok baskı kurulan çocuklarda ilerleyen yaşlarda yeme bozuklukları daha sık görülmektedir [5 ve 6].

Erken yaşlarda görülen yeme bozuklukları çoğu kez okul çağında ortaya çıkmaktadır. Hafif ve orta derecedeki yetersizlikler okul başarısını olumsuz yönde etkilemekte, verimliliği azaltmakta, çocuğun okul başarısının düşmesine yol açmaktadır. Bunun yanı sıra aşırı besin tüketimi çeşitli sağlık sorunları için uygun bir zemin hazırlanmasına neden olmaktadır [7].

Bu çalışmada okul öncesi dönem çocuğu olan annelerin çocuklarını besleme uygulamaları ile çocukların yemek yeme davranışlarının değerlendirilmesi amaçlanmıştır.

\section{Materyal ve Metod}

Araştırma evrenini, Ankara ilinde bulunan ve izin alınabilen beş anaokulu, örneklemi ise bu anaokullarına devam etmekte olan 2-6 yaş grubu çocuğu olan anneler oluşturmuştur. Çalışma kesitsel tipte bir durum saptama çalışmasıdır. Çalışmaya anaokullarına devam eden çocukların annelerinin $(n=400)$ tamamının katılması hedeflenmiştir. Anket formları anaokullarına gelen bütün çocukların annesine ulaştırılmıştır. Ancak verilerin eksik ya da hatalı doldurulması veya ailelerin katılmayı istememesi gibi nedenlerle 145 anket çalışmadan çıkarılmış 255 anket değerlendirmeye alınmıştır.

Çalışma verilerinin toplanmasında anket formu kullanılmıştır. Bu formda anne ve çocuğa ilişkin genel bilgiler ile annelerin çocuk besleme uygulamaları, çocukluk çağı obezitesi eğilimi ile çocukların yeme davranışlarını belirlemeye yönelik sorular yer almaktadır. Annelerin çocuk besleme uygulamaları Birch ve arkadaşları (2001) tarafından geliştirilen, geçerlik ve güvenilirliği Camcı ve arkadaşları (2014) tarafından yapılan Child Feeding Questionnaire (CFQ) ölçeği kullanılarak belirlenmiştir [8 ve 9]. Bu ölçek 21 ifadeyi içeren ve annelerin çocuk besleme tutum ve uygulamalarını belirlemeye yönelik bir ölçektir. Ölçek algılanan sorumluluk, izlem, çocuk ağırlığı hakkındaki ilgi, kısıtlama ve yeme baskısı alt boyutlarından oluşmaktadır. Ölçek formunda yer alan ifadeler 5’li likert tipi olup her zaman ve katılıyorum 5 , 
çoğunlukla ve biraz katılıyorum 4, bazen ve kararsızım 3, nadiren ve biraz katılmıyorum 2, hiç ve katılmıyorum 1 olarak puanlanmıştır. Ölçeğin Cronbach’s Alfa katsayısı 0.80 olarak bulunmuştur. Çocuklarda yeme davranışı, Wardle ve arkadaşları (2001) tarafından geliştirilen, geçerlik ve güvenilirliği Yıılmaz ve arkadaşları (2011) tarafından yapılan ÇYDA ölçeği kullanılarak belirlenmiştir [10 ve 11]. Bu ölçek ise 35 ifadeyi içeren ve çocuğun besine yaklaşımı ve sakındığı davranışları belirlemeyi amaçlayan bir ölçektir. Ölçek besin heveslisi, duygusal aşırı yeme, besinden keyif alma, içme tutkusu, tokluk heveslisi, yavaş yeme, duygusal az yeme ve besin seçiciliği alt boyutlarından oluşmaktadır. Ölçek likert tipi olup, ölçekte yer alan ifadeler için her zaman 5, sık sık 4, bazen 3, nadiren 2, asla 1 olarak puanlandırılmıştır. Ölçeğin Cronbach's Alfa katsayısı 0.71 olarak bulunmuştur.

Araştırma verileri Statistical Package for the Social Sciences (SPSS) paket programı kullanılarak değerlendirilmiştir. Anket sorularının değerlendirilmesinde mutlak ve \% değerleri gösteren tablolar hazırlanmış, istatistiksel olarak normal dağılım gösteren verilerde iki ortalama arasındaki farkın önemlilik testi (Student T test) ve alt boyutlar arasındaki ilişkinin incelenmesinde Pearson korelasyon analizi kullanılmıştır.

\section{Bulgular}

Araştırmaya konu olan çocukların \%47.8'i kız, \%52.2'si erkektir. Çocukların çoğunluğu (\%78.8'i) 3 yaşın üzerindedir. Çocukların yarıdan fazlasının (\%58.8) bir kardeşi olup, \%41.2'si ailenin tek çocuğudur. Çalışmaya katılan çocukların yarısından çoğu (\%58.4) ailelerin birinci çocuğu, \%36.5’i ikinci, \%5.1’i ise üçüncü ve daha sonra doğan çocuklardır. Çocukların \%41.1'ine kreşe başlamadan önce anneanne/babaanneleri, \%26.5'ine anneleri, \%26.5'ine bakıcı ve \%0.3'üne ablası veya diğer yakın akrabalarının baktıkları belirlenmiştir.

Çalışmaya katılan annelerin \%58.0’ı üniversite, \%20.8'i lise, \%16.9’u lisansüstü ve \%4.3'ü ilköğretim mezunu olup, \%82.4’ü çalışmaktadır.

Tablo 1 incelendiğinde de görülebileceği gibi annelerin çocuklarının vücut ağırlıklarına yönelik algıları sorgulanmış, genel olarak normal oldukları şeklinde yanıtlar alınmıştır. Bununla birlikte annelerin \%17.6'sı 0-1 yaşta çocuğunu hafif şişman bulurken, 2-3 yaşta \%11.8'i, 3-4 yaşta \%12.9'u, 5 yaş ve üzerinde ise \%12.2'si çocuğunu zayıf olarak değerlendirmektedir.

Tablo 1. Annelerin çocuklarının farklı yaş dönemlerindeki vücut ağırlığına yönelik algısı (\%)

\begin{tabular}{cccccccccccc}
\hline \multirow{2}{*}{ Yaş aralığı } & \multicolumn{2}{c}{ Aşırı zayıf } & \multicolumn{2}{c}{ Zayıf } & \multicolumn{2}{c}{ Normal } & \multicolumn{2}{c}{ Hafif şişman } & \multicolumn{2}{c}{ Şişman } \\
\cline { 2 - 10 } & $\mathbf{n}$ & $\mathbf{\%}$ & $\mathbf{n}$ & $\mathbf{\%}$ & $\mathbf{n}$ & $\mathbf{\%}$ & $\mathbf{n}$ & $\mathbf{\%}$ & $\mathbf{n}$ & $\mathbf{\%}$ \\
\hline $\mathbf{0 - 1}$ & 6 & 2.4 & 21 & 8.2 & 175 & 68.6 & 45 & 17.6 & 8 \\
$\mathbf{2 - 3}$ & 2 & 0.8 & 30 & 11.8 & 201 & 78.8 & 21 & 8.2 & 1 & 0.4 \\
$\mathbf{3 - 4}$ & 1 & 0.4 & 33 & 12.9 & 205 & 80,4 & 16 & 6,3 & - & - \\
$\mathbf{5}$ ve üzeri & - & - & 31 & 12.2 & 208 & 81.6 & 13 & 5.1 & 3 & 1.2 \\
\hline
\end{tabular}

\section{Çocuk besleme uygulamaları ve çocuklarda yeme davranışı}

Annelerin çocuk besleme uygulamaları ölçeğine verdikleri yanıtlar Tablo 2'de verilmiştir. 
Tablo 2. Annelerin çocuklarını besleme uygulamalarına ilişkin veriler (\%).

\begin{tabular}{|c|c|c|c|c|c|}
\hline Algllanan Sorumluluk & 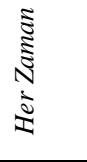 & $\frac{\sqrt{5}}{0}$ & $\underset{\widetilde{\Xi}}{\tilde{\Xi}}$ & $\frac{\tilde{2}}{\grave{2}}$ & 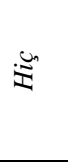 \\
\hline Çocuğunuz evdeyken, onu ne siklıkla siz yedirirsiniz? & 24.7 & 22.0 & 32.9 & 14.9 & 5.5 \\
\hline Çocuğunuzun yediği yiyeceğin miktarına ne sıklıkla siz karar verirsiniz? & 24.7 & 25.1 & 28.2 & 13.3 & 8.2 \\
\hline $\begin{array}{l}\text { Çocuğunuzun doğru yiyecek çeşitlerini yemeye karar vermesinde ne siklıkla siz } \\
\text { sorumlusunuz? } \\
\text { İlem }\end{array}$ & 50.2 & 32.5 & 12.9 & 3.9 & 0.4 \\
\hline $\begin{array}{l}\text { Çocuğunuzun yediği şekerli besinlerden (dondurma, kek, şeker, pasta) ne siklıkla } \\
\text { haberiniz olur? }\end{array}$ & 78.4 & 16.5 & 3.9 & 1.2 & - \\
\hline Çocuğunuzun yediği abur cubur besinlerden ne slklıkla haberiniz olur? & 75.3 & 18.8 & 3.9 & 2.0 & - \\
\hline $\begin{array}{l}\text { Çocuğunuzun yediği yüksek yağlı besinlerden ne sıklıkla haberiniz olur? } \\
\text { Çocuk Ağırlığı Hakkında İlgi }\end{array}$ & 78.4 & 16.1 & 3.5 & 1.6 & 0.4 \\
\hline $\begin{array}{l}\text { Çocuğunuzun siz yanında değilken çok yemesi konusunda ne slklıkla } \\
\text { endișelenirsiniz? }\end{array}$ & 14.9 & 7.5 & 22.0 & 18.8 & 36.9 \\
\hline $\begin{array}{l}\text { Çocuğunuzun arzu edilen kiloyu korumak için diyet yapmak zorunda olmasından } \\
\text { ne siklıkta endişelenirsiniz? }\end{array}$ & 12.5 & 3.5 & 9.8 & 11.8 & 62.4 \\
\hline \multirow[t]{3}{*}{ Çocuğunuzun kilolu olma konusu sizi endişelendirir mi? } & 29.4 & 5.5 & 19.6 & 12.2 & 33.3 \\
\hline & 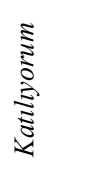 & 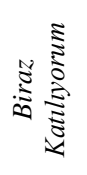 & 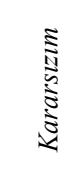 & 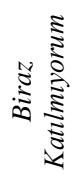 & 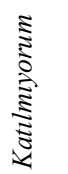 \\
\hline & \multicolumn{5}{|c|}{ Kısitlama } \\
\hline $\begin{array}{l}\text { Çocuğumun şekerli besinleri (dondurma, kek, şeker, pasta) gereğinden çok } \\
\text { yemediğinden emin olmalıyım }\end{array}$ & 68.6 & 28.6 & - & 1.6 & 1.2 \\
\hline Çocuğumun yağlı besinleri gereğinden çok yemediğinden emin olmalıyım & 67.8 & 29.8 & 1.6 & 0.4 & 0.4 \\
\hline $\begin{array}{l}\text { Çocuğumun kendi sevdiği yiyecekleri (favori besinlerini) gereğinden çok } \\
\text { yemediğinden emin olmalıyım }\end{array}$ & 52.9 & 38.4 & 5.1 & 2.7 & 0.8 \\
\hline Bazl yiyecekleri bilerek çocuğumun ulaşamayacă̆ yerlerde saklarım. & 37.3 & 32.9 & 4.7 & 14.9 & 10.2 \\
\hline $\begin{array}{l}\text { Çocuğumun yaptığı iyi davranışlara ödül olarak ona şekerli besinler (dondurma, } \\
\text { kek, şeker, pasta) veririm. }\end{array}$ & 7.1 & 33.7 & 21.6 & 22.7 & 14.9 \\
\hline $\begin{array}{l}\text { Çocuğuma istediğim şeyi yaptırabilmek için ona kendi sevdiği favori besinini } \\
\text { sunarım }\end{array}$ & 6.3 & 24.7 & 18.4 & 32.9 & 17.6 \\
\hline $\begin{array}{l}\text { Eğer çocuğumun yediklerini kontrol etmezsem veya ona rehberlik yapmazsam, çok } \\
\text { fazla abur cubur yer }\end{array}$ & 36.5 & 25.1 & 5.5 & 21.2 & 11.8 \\
\hline $\begin{array}{l}\text { Ĕ̆er çocuğumun yediklerini kontrol etmezsem veya ona rehberlik yapmazsam, çok } \\
\text { fazla kendi favori besinini yer } \\
\text { Yeme Baskısı }\end{array}$ & 36.5 & 34.9 & 6.3 & 17.3 & 5.1 \\
\hline Çocuğum tabağındaki yemeği her zaman bitirmelidir & 22.7 & 25.1 & 14.5 & 30.2 & 7.5 \\
\hline $\begin{array}{l}\text { Çocuğumun yeterince yediğinden emin olmak için özellikle dikkatli olmak } \\
\text { zorundayım }\end{array}$ & 29.8 & 40.4 & 12.2 & 16.1 & 1.6 \\
\hline Çocuğum aç değilim dese bile, ben ona yemek yedirmeye uğraşırım & 9.4 & 16.9 & 12.9 & 36.9 & 23.9 \\
\hline $\begin{array}{l}\text { Ĕger çocuğumun yediklerini kontrol etmezsem veya ona rehberlik yapmazsam, } \\
\text { yemesi gerekenden daha az yer }\end{array}$ & 23.9 & 36.9 & 10.6 & 19.6 & 9.0 \\
\hline
\end{tabular}

Tabloda da görülebileceği gibi çocukların \%24.7'sine her zaman anneleri yemek yedirmekte ve çocukların ne kadar yiyeceğine karar vermektedir. Annelerin \%50.2'si çocuklarının doğru besinleri tercih etmesinden her zaman kendini sorumlu tutmakta ve çocuklarının yediği şekerli (\%78.4), abur cubur (\%75.3) ve yağ içeriği yüksek besinleri (\%78.4) kontrol etmektedirler.

Annelerin \%29.4'ünün çocuklarının vücut ağırlıkları hakkında endişe duydukları belirlenmiştir. Annelerin çoğunlukla hiçbir zaman yanıtını verdikleri ifadeler, birlikte değilken çok yemesi konusunda endişe duymadığı (\%36.9) ve vücut ağırlığını korumak için diyet yapmak zorunda olmadığıdır (\%62.4).

Çocuğunun gereğinden fazla şekerli besin (dondurma, kek, şeker, pasta) yemediğinden kesinlikle emin olmak isteyen annelerin oranı \%68.6, yağlı besin yemediğinden kesinlikle emin olmak isteyen annelerin oranı \%67.8, çocuğun sevdiği yiyecekleri yemediğinden kesinlikle emin olmak isteyen annelerin oranı \%52.9'dur. Bazı yiyecekleri bilerek çocuğunun ulaşamayacağı yerde saklayan anneler çoğunluktadır (\%37.3). Çocuğunun yaptığı iyi davranışa ödül olarak şekerli besinler (dondurma, kek, şeker, pasta vb.) verilmesi konusuna katılan annelerin oranı çoğunlukta olup \%33.7’dir. 


\section{Nevşehir Bilim ve Teknoloji Dergisi (2018), 7(1) 1-13}

Çocuğa istediği şeyi yaptırabilmek için sevdiği besinlerin sunulmasına annelerin \%32.9'u katılmamaktadır. Annelerin büyük bir çoğunluğu çocuklarının yediklerini kontrol etmezse veya ona rehberlik yapmazsa çok fazla abur cubur (\%36.5) ve kendi sevdikleri besinleri (\%36.5) tüketeceğini düşünmektedir. Çocuğunun tabağındaki besini her zaman bitirmesi gerektiğine annelerin \%30.2'si katılmıyorum yanıtını vermiştir. Annelerin \%40.4'ü kendilerini çocuklarının yeterince yediğinden emin olmak için özellikle dikkatli olmak zorunda hissetmektedir. Çocuk aç değilse bile ona yemek yedirmeye her zaman uğraşırım yanıtını veren annelerin oranı \%9.4, çok sık uğraşırım yanıtını verenlerin oranı \%16.9'dur. Annelerin \%23.9'u çocuklarını kontrol etmezse veya ona rehberlik yapmazsa onun gereğinden az yiyeceğini düşünmektedir. Annelerin çocuklarının yeme davranışlarına ilişkin verdikleri yanıtlar Tablo 3'de verilmiştir.

Tablo 3. Çocukların yeme davranışlarına ilişkin veriler (\%) ölçeği ve alt boyutları

\begin{tabular}{|c|c|c|c|c|c|}
\hline & $\frac{\pi}{4}$ & 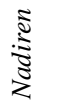 &  & $\begin{array}{l}\frac{\omega}{5} \\
\frac{\omega}{\omega}\end{array}$ & 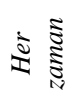 \\
\hline \multicolumn{6}{|l|}{ Besin heveslisi } \\
\hline 12.Çocuğum sürekli yiyecek bir şeyler ister & 16.9 & 35.7 & 32.2 & 11.0 & 4.3 \\
\hline 14.Eğer izin verilirse çocuğum daha çok yer & 68.2 & 19.2 & 9.4 & 1.6 & 1.6 \\
\hline 27.Çocuğum tok olsa bile en çok sevdiği yiyeceği yer & 29.4 & 29.0 & 27.8 & 6.7 & 7.1 \\
\hline 33. İin verilse çocuğum tüm zamanın yemek yiyerek geçirir & 57.6 & 29.0 & 8.2 & 2.0 & 3.1 \\
\hline 19.Çocuğum yemek zamanını iple çeker & 20.8 & 31.0 & 34.9 & 9.0 & 4.3 \\
\hline \multicolumn{6}{|l|}{ Duygusal așirt yeme } \\
\hline 2.Çocuğum üzüldüğünde normalden çok yemek yer & 76.1 & 15.7 & 7.1 & 1.2 & - \\
\hline 13. Çocuğum sıkıntılı, rahatsız daha fazla yer & 80.4 & 14.1 & 3.9 & 0.4 & 1.2 \\
\hline 15.Çocuğum kayglliyken, huzursuzken, endişeliyken daha çok yer & 77.6 & 14.5 & 6.7 & 0.4 & 0.8 \\
\hline 25.Çocuğum yapacak bir şeyi olmadı̆̆ında daha fazla yiyor & 58.4 & 17.6 & 16.5 & 5.1 & 2.4 \\
\hline \multicolumn{6}{|l|}{$\begin{array}{l}\text { Besinden keyif alma } \\
\end{array}$} \\
\hline 1.Çocuğum yemek yemeyi sever & 2.4 & 15.3 & 34.9 & 27.5 & 20.0 \\
\hline 3.Çocuğum çok iştahlıdır & 21.2 & 18.0 & 45.5 & 11.0 & 4.3 \\
\hline 4.Çocuğum yemekleri hızlı tüketir & 28.2 & 31.4 & 31.0 & 5.1 & 4.3 \\
\hline 5.Çocuğum yemeğe önem verir, yemeklerle ilgilidir & 14.1 & 24.3 & 33.3 & 16.5 & 11.8 \\
\hline 20.Çocuğum yemek yemekten hoşlanır & 7.1 & 11.8 & 29.4 & 23.9 & 27.8 \\
\hline \multicolumn{6}{|l|}{ İ̧me tutkusu } \\
\hline 6.Çocuğum sürekli bir içecek ister & 6.3 & 25.9 & 32.5 & 20.4 & 14.9 \\
\hline 28. Çocuğuma izin verilirse gün boyunca bir şeyler içer & 43.9 & 25.9 & 16.9 & 7.8 & 5.5 \\
\hline 30. Çocuğum yemek yerine daima içecek bir şeyleri tercih eder & 41.2 & 27.8 & 20.0 & 7.1 & 3.9 \\
\hline \multicolumn{6}{|l|}{ Tokluk heveslisi } \\
\hline 32.Çocuğum yiyeceği tatmadan tadının kötü olduğunu söyleyerek yemez & 15.7 & 22.7 & 32.5 & 18.8 & 10.2 \\
\hline 7.Çocuğum yeni yiyecekleri başlangıçta reddeder & 6.3 & 22.7 & 42.4 & 22.7 & 5.9 \\
\hline 17. Çocuğum yemek sonunda(bitiminde) tabağında yemek birakır & 5.1 & 20.0 & 49.0 & 15.7 & 10.2 \\
\hline 22.Çocuğum yemekle mutlu etmek zordur & 14.1 & 31.0 & 35.3 & 10.6 & 9.0 \\
\hline 24.Çocuğum çabuk doyar & 3.5 & 5.5 & 25.1 & 42.7 & 23.1 \\
\hline 26. Çocuğum yemeği bitmeden doyar & 33.3 & 17.6 & 22.4 & 18.0 & 8.6 \\
\hline 29. Ĕger çocuğum yemekten önce aperatif bir şeyler yemişse yemek yemez & 8.6 & 15.3 & 33.3 & 26.3 & 16.5 \\
\hline \multicolumn{6}{|l|}{ Yavaş yeme } \\
\hline 18.Çocuğumun yemeğini bitirmesi 30 dakikadan fazla sürer & 18.4 & 23.1 & 30.2 & 18.8 & 9.4 \\
\hline 8.Çocuğum yemekleri yavaş yer & 5.1 & 12.2 & 29.0 & 29.8 & 23.9 \\
\hline 34.Çocuğum yemek süresi boyunca yavaş, daha yavaş yer & 13.3 & 16.9 & 31.8 & 20.0 & 18.0 \\
\hline \multicolumn{6}{|l|}{ Duygusal az yeme } \\
\hline 11.Çocuğum yorgunken normalden daha az yer & 8.6 & 14.9 & 34.5 & 28.2 & 13.7 \\
\hline 9.Çocuğum sinirliyken, kuzgınken normalden daha az yer & 20.4 & 17.3 & 31.4 & 17.6 & 13.3 \\
\hline 23. Çocuğum mutsuz olduğu zaman daha az yer & 20.0 & 19.6 & 31.4 & 14.9 & 14.1 \\
\hline 21.Çocuğum mutlu olduğunda daha çok yemek yer & 16.5 & 24.3 & 35.7 & 4.9 & 8.6 \\
\hline \multicolumn{6}{|l|}{ Besin seçiciliği } \\
\hline 10.Çocuğum yeni yiyeceklerin tadına bakmaktan zevk alır & 15.3 & 32.5 & 38.0 & 10.2 & 3.9 \\
\hline 16. Çocuğum çok çeşitli yemeklerden hoşlanır & 17.3 & 23.1 & 40.0 & 12.5 & 7.1 \\
\hline 31.Çocuğum daha önce tatmadığ bir yiyeceği yer & 12.2 & 31.8 & 42.4 & 9.4 & 4.3 \\
\hline
\end{tabular}

Tablo 3'den görüldüğü gibi anneler bazen çocuklarının yemek yemeyi sevdiğini (\%34.9) ve yemeklerle ilgili olduğunu (\%33.3), tabağında yemek bıraktığını (\%49.0), yeni yiyeceklerin tadına bakmaktan zevk aldığını (\%38.0) düşünürken, \%42.4'ü yeni yiyecekleri reddettiğini, \%35.3'ü bazen yemekle mutlu etmenin zor olduğunu düşünmektedir. Anneler çocuklarının sıklıkla yemekleri yavaş yediğini (\%29.8), genel olarak çocuklarının yemekten önce bir şeyler atıştırdığ zaman yemek yemediğini düşünmektedir. Annelerin \%41.2'si çocukların yemek yerine içecek tercih etme 
durumuna asla yanıtını vermiştir. Annelerin \%42.4'ü çocuklarının daha önce tatmadığı bir yiyeceği bazen yiyeceğini, \%12.2'si asla yemeyeceğini ifade etmektedir. Annelerin \%31.8'i çocuklarının yemeği çok yavaş yediğini söylemektedir.

Ölçekte yer alan bazı ifadeler çocuğun duygu durumunun beslenmesi üzerine etkisini belirlemeyi amaçlamaktadır. Anneler genel olarak çocuklarının üzüntülü olmasının, hasta ve kaygılı olmasının yemek yemelerini etkilemediğini ifade etmektedirler (\%76.1). Çocuğu sinirliyken (bazen) normalden daha az yediğini düşünen annelerin oranı \%31.4'dür. Bununla birlikte annelere göre çocukların \%35.7'si mutlu olduğunda (bazen) daha çok yemektedir. Anneler \%45.5'i çocuklarının (bazen) çok iştahlı olduğunu düşünmektedir. Anneler çocuklarının yemekleri nadiren hızlı tükettiğini ifade etmektedir (\%31.4). Büyük bir çoğunlukla anneler izin verilirse çocuklarının daha fazla yemeyeceğini (\%68.2) düşünmektedir. Anneler sıklıkla (\%42.7) çocuklarının kolaylıkla doyduğunu ifade etmektedir. Annelerin \%58.4'ü “çocuğumun yapması gereken başka bir şey yoksa daha fazla yer” ifadesine, \%29.4’ü “çocuğum tok olsa bile en çok sevdiği yiyeceği yer" ifadesine asla şeklinde yanıt vermiştir. Anneler çocuğuna izin verilse bile bir şeyler yiyip (\%57.6) içmeyeceğini (\%43.9) düşünmektedir. Annelerin çocuklarını besleme uygulamalarına ilişkin toplam puanlar Tablo 4'te verilmiştir.

Tablo 4. Annelerin çocuklarını besleme uygulamalarına ilişkin toplam puanlar

\begin{tabular}{|c|c|c|c|c|}
\hline & $\begin{array}{c}\text { Erkek } \\
\text { Ort } \pm \text { s.s. }\end{array}$ & $\begin{array}{c}\text { Kız, } \\
\text { Ort } \pm \text { s.s. }\end{array}$ & $\begin{array}{l}\text { Toplam } \\
\text { Ort } \pm \text { s.s. }\end{array}$ & p değeri \\
\hline Algilanan Sorumluluk & $11.0 \pm 2.4$ & $11.3 \pm 2.4$ & $11.1 \pm 2.4$ & .272 \\
\hline İzlem & $13.9 \pm 1.8$ & $14.2 \pm 1.4$ & $14.1 \pm 1.6$ & .107 \\
\hline Çocuk Ă̆ırlı̆̆ı Hakkında İlgi & $6.9 \pm 3.4$ & $7.4 \pm 3.3$ & $7.2 \pm 3.4$ & .304 \\
\hline Kisitlama & $30.2 \pm 5.2$ & $30.4 \pm 4.8$ & $30.3 \pm 4.9$ & .717 \\
\hline Yeme Baskısı & $13.1 \pm 3.7$ & $12.9 \pm 3.6$ & $13.0 \pm 3.7$ & .550 \\
\hline
\end{tabular}

Tablo 4 incelendiğinde, anneler kısıtlama alt boyutundan ortalama $30.3 \pm 4.9$ puan, yeme baskısı alt boyutundan 13.0 \pm 3.7 puan almışlardır. Cinsiyetler arasında anlamlı farklılık bulunamamıştır ( $>0.05)$. Annelerin çocuklarının yeme davranışlarına ilişkin toplam puanları Tablo 5 'te verilmiştir.

Tablo 5. Çocukların yeme davranışlarına ilişkin toplam puanlar

\begin{tabular}{|c|c|c|c|c|}
\hline & $\begin{array}{r}\text { Erkek } \\
\text { Ort } \pm \text { s.s. }\end{array}$ & $\begin{array}{c}\text { Kiz } \\
\text { Ort } \pm \text { s.s. }\end{array}$ & $\begin{array}{c}\text { Toplam } \\
\text { Ort } \pm \text { s.s. }\end{array}$ & p de ğeri \\
\hline Besin heveslisi & $10.5 \pm 3.5$ & $10.2 \pm 3.3$ & $10.4 \pm 3.4$ & .605 \\
\hline Duygusal aşırı yeme & $5.6 \pm 2.0$ & $5.7 \pm 2.0$ & $5.6 \pm 2.0$ & .610 \\
\hline Besinden keyif alma & $13.8 \pm 3.1$ & $13.4 \pm 2.8$ & $13.6 \pm 2.9$ & .258 \\
\hline İcme tutkusu & $7.3 \pm 2.5$ & $7.1 \pm 2.6$ & $7.2 \pm 2.5$ & .585 \\
\hline Tokluk heveslisi & $21.1 \pm 4.5$ & $21.1 \pm 4.8$ & $21.1 \pm 4.6$ & .973 \\
\hline Yavaş yeme & $9.1 \pm 2.8$ & $9.7 \pm 3.0$ & $3.4 \pm 2.9$ & .113 \\
\hline Duygusal az yeme & $11.6 \pm 3.7$ & $11.7 \pm 3.6$ & $11.6 \pm 3.6$ & .819 \\
\hline Besin seçiciliği & $7.8 \pm 2.6$ & $7.8 \pm 2.3$ & $7.8 \pm 2.5$ & .835 \\
\hline
\end{tabular}

Tablo 5'ten de görülebildiği gibi çocuklar besin seçiciliği alt boyutundan ortalama $7.8 \pm 2.5$ puan alırken, tokluk heveslisi alt boyutundan 21.1 \pm 4.6 puan almışlardır. Cinsiyetler arasında istatistiksel olarak anlamlı bir farklılığa rastlanmamıştır ( $\mathrm{p}>0.05)$. Annelerin çocuklarını besleme uygulamaları ve çocukların yeme davranışlarına ilişkin alt boyutlar arasındaki ilişkiye ait korelasyon değerleri Tablo 6'da verilmiştir. 
Tablo 6. Annelerin çocuklarını besleme uygulamaları ve çocukların yeme davranışlarına ilişkin alt boyutlar arasındaki ilişkiye ait korelasyon

\begin{tabular}{|c|c|c|c|c|c|c|c|c|c|c|c|c|c|}
\hline & 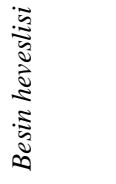 & 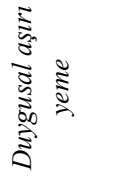 & 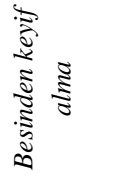 & 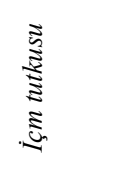 & 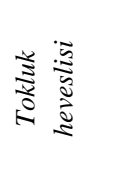 & 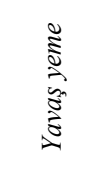 & 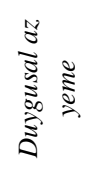 & ڤ్ & 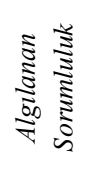 & $\frac{\Sigma}{\sqrt{ \pm}}$ & 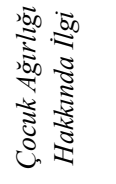 & 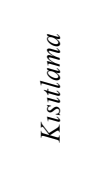 & 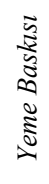 \\
\hline Besin heveslisi & 1 & & & & & & & & & & & & \\
\hline $\begin{array}{l}\text { Duygusal aşırt } \\
\text { yeme }\end{array}$ & $.519 * *$ & 1 & & & & & & & & & & & \\
\hline $\begin{array}{l}\text { Besinden keyif } \\
\text { alma }\end{array}$ & $.537^{* *}$ & $.326 * *$ & 1 & & & & & & & & & & \\
\hline$\dot{I}_{\text {I̧me tutkusu }}$ & $.212^{* *}$ & $.208 * *$ & -.011 & 1 & & & & & & & & & \\
\hline $\begin{array}{l}\text { Tokluk } \\
\text { heveslisi }\end{array}$ & $-.142 *$ & -.050 & $-.287 * *$ & $.436^{* *}$ & 1 & & & & & & & & \\
\hline Yavaş yeme & $-.206^{* *}$ & -.106 & $-.426 * *$ & $.136 *$ & $.423 * *$ & 1 & & & & & & & \\
\hline $\begin{array}{l}\begin{array}{l}\text { Duygusal az } \\
\text { yeme }\end{array} \\
\end{array}$ & $.133 *$ & .122 & .007 & $.299 * *$ & $.374 * *$ & $-.179 * *$ & 1 & & & & & & \\
\hline $\begin{array}{l}\text { Besin } \\
\text { seçiciliğ } i\end{array}$ & $.276 * *$ & $.123^{*}$ & $.413^{* *}$ & $-.163 * *$ & $-.492^{* *}$ & $-.275^{* *}$ & -.045 & 1 & & & & & \\
\hline $\begin{array}{l}\text { Algilanan } \\
\text { sorumluluk }\end{array}$ & -.076 & .005 & $-.230 * *$ & $.140 *$ & $.363 * *$ & $.175 * *$ & .060 & -.009 & 1 & & & & \\
\hline İzlem & -.030 & -.087 & .085 & $-.146 *$ & $-176^{* *}$ & -.043 & -.001 & $.137 *$ & .069 & 1 & & & \\
\hline $\begin{array}{l}\text { Çocuk ağgrllğ̆ } \\
\text { hakkinda Ilgi }\end{array}$ & $.180 * *$ & $.176^{* *}$ & .070 & .012 & .071 & -.019 & -.009 & -.007 & $.243^{* *}$ & -.036 & 1 & & \\
\hline Kisitlama & $.131 *$ & .105 & -.046 & $.187^{* *}$ & $.332 * *$ & .109 & $.208 * *$ & -.064 & $.198 * *$ & $\begin{array}{l}-.082 \\
\end{array}$ & $.347^{* *}$ & 1 & \\
\hline Yeme baskisl & -.076 & .005 & $-.230 * *$ & .140 & $.363^{* *}$ & $.243^{* *}$ & .112 & $.196^{* *}$ & $.428 * *$ & -.076 & $.306^{* *}$ & $.383^{* *}$ & 1 \\
\hline
\end{tabular}

Annelerin yeme baskısı ile çocukların besinden keyif alma ( $\mathrm{r}=-.230 ; \mathrm{p}<0.01)$ davranışı alt boyutu negatif yönlü, besin seçiciliği $(r=-.196 ; p<0.01)$, tokluk heveslisi $(r=.363 ; p<0.05)$, yavaş yeme $(r=.243 ; p<0.01)$ davranışı alt boyutunun pozitif yönlü korelasyon gösterdiği belirlenmiştir. Annelerin yeme baskısı ile kısıtlama $(r=.306 ; p<0.01)$ ve çocuk ağırlığı hakkındaki ilgi $(\mathrm{r}=.383 ; \mathrm{p}<0.05)$ davranışı alt boyutlarının pozitif yönlü korelasyon gösterdiği belirlenmiştir. Annelerin kısıtlama davranışı ile çocukların tokluk heveslisi davranışı alt boyutu pozitif yönlü korelasyon $(\mathrm{r}=.332 ; \mathrm{p}<0.01)$ göstermektedir. Çocukların yavaş yeme davranışı ile besinden keyif alma $(r=-.426 ; p<0.01)$ davranışı alt boyutu negatif yönlü, tokluk heveslisi $(r=.423 ; \mathrm{p}<0.01)$ davranışı pozitif yönlü korelasyon göstermektedir (Tablo 6).

\section{Tartışma ve Sonuç}

Bu çalışma, okul öncesi dönem çocuğu olan annelerin çocuklarını besleme uygulamalarını ve bu uygulamaların çocukların yeme davranışı üzerine etkisini belirlemek amacıyla yapılmıştır. Annelerin büyük çoğunluğu çocuklarının doğru besinleri tercih etmesinden her zaman kendini sorumlu tutmakta, çocuklarının yediği şekerli, abur cubur ve yüksek yağlı besinlerden her zaman haberdar olmak istemektedir. Aynı zamanda annelerin yarıdan fazlası genel olarak çocuklarının kilolu olması konusunda endişe duyduklarını belirtmişlerdir. İngiltere'de yapılan bir çalışmada okul öncesi eğitimi alan 5 yaş altı çocuklarda uygun gıdalarla dengeli ve sağlıklı beslenmenin ilgi ve destek gerektirdiği sonucuna varılmıştır [12]. Yapılan bir başka çalışmada da anaokulu tabanlı beslenme eğitiminin okul öncesi çocukların beslenmelerinde ve kendi kişisel beslenme alışkanlıklarında faydalı değişiklikler meydana getirdiği ve annelerin de yaşam biçimini beslenme konusunda olumlu yönde değiştirdiği bulunmuştur [13]. Bu çalışmada da, annelerin çocuklarının beslenmesiyle ilgili oldukları saptanmıştır. Ancak bu çalışmaya konu olan annelerin beslenme konusunda çocuklarını 


\section{Nevşehir Bilim ve Teknoloji Dergisi (2018), 7(1) 1-13}

kontrol etmeye çalıştıkları ve yeme konusunda baskı kurdukları da görülmektedir (Tablo 2). Buna bağlı olarak çocuklar da genel olarak yemek konusunda seçicidirler. Çocuklar yeni besinleri tüketme, tabağındaki besinleri bitirme, yemeklerden memnun olma, yeni tatlar denemeyi ancak besini sevdiği takdirde gerçekleştirmektedirler (Tablo 3). Yapılan bir çalışmada annelerin bir bölümünün çocuklarının beslenmesini kontrol etmek için yeme baskısı ve kısıtlama davranışını sıklıkla kullandığı gösterilmiştir [14]. Diğer bir çalışmada da çocuklarının kilosu hakkında endişe duyan anneler çocuklarını daha fazla kontrol altında tutmak istemektedir [15]. Bu çalışmada çocuğun düşük ağırlıklı olması endişesi ile yeme baskısı; kısıtlama ile çocuk ağırlığı hakkındaki ilgi pozitif ilişkili bulunmuştur. Annenin yeme baskısı ile çocuğun besin seçiciliği pozitif ilişkili bulunmuştur. Yapılan bir çalışmada da çocuk ağırlığı hakkındaki ilgi ile kısıtlama ve yeme baskısı pozitif yönlü ilişki göstermektedir [16]. Yapılan bir diğer çalışmada kısıtlama ve yeme baskısı pozitif yönlü ilişki göstermektedir [17]. 2-4 yaş aralığında çocuğa sahip 183 anne ile yapılan çalışmada; çocuğun düşük ağırlıklı olması endişesi ile yeme baskısı, kısıtlama ile çocuğun fazla kilolu olma endişesi ve çocuğun besin seçiciliği ile annenin yeme baskısı pozitif ilişkili bulunmuştur [18]. Bu çalışmada annenin yeme baskısı ile çocuğun besinden keyif alması negatif ilişkili, besin seçiciliği pozitif ilişkili bulunmuştur (Tablo 6). Tokyo'da anaokullarına devam eden 3-6 yaş aralığında çocuğu olan 617 annenin katıldığı bir çalışmada; besinden daha az keyif alma ve besin seçiciliği annenin yeme baskısı ile ilişkili bulunmuştur. Besine karşı seçici ve isteksiz davranan çocukların annelerinin daha fazla yeme baskısı yaptığı bilinmektedir [19]. Çalışmada annelerin yeme baskısı ile çocukların tokluk heveslisi ve yavaş yeme davranışı ile pozitif ilişkilidir (Tablo 6). 1-5 yaş aralığında çocuğa sahip 203 anne ile yapılan bir başka çalışmada da; anneler yavaş yeme, besinden daha az keyif alma ve tokluk heveslisi (yeme isteksizliği) gibi iştahsızlık belirtileri gösteren çocuklarına daha fazla yeme baskısı yapmakta iken; duygusal aşırı yeme ve besin hevesli (sürekli yeme isteği) gibi yüksek iştah belirtileri gösteren çocuklarına daha fazla sınırlama yapmaktadır ve çocuklarını kontrol altında tutmak istemektedirler [20]. 478 ebeveyn ile yapılan bir çalışmada; ebeveynlerin sınırlama davranışı, çocuklarının besin tercihlerinden daha çok onların ağırlıklarından endişe duymaları ile ilişkili bulunmuştur. İştahsız ve besin seçen çocuğa sahip ebeveynler daha fazla yeme baskısı yaparken çocuklarının fazla kilolu olmasından endişe duyan ebeveynler daha fazla sınırlayıcı davranmaktadır [21]. Yapılan diğer çalışmalarda zayıf çocuğa sahip ebeveynler çocuklarına daha çok yeme baskısı yapmakta iken; kilolu ve şişman çocuğa sahip ebeveynler daha az yeme baskısı yapmaktadır ve daha fazla yiyecek yasaklamaktadır [8 ve 9]. Araştırmada çocukların besin seçiciliği ve annelerin baskı kurmasına yönelik sorulan ifadelere göre annelerin genellikle kontrol etme isteğinin fazla olduğu belirlenmiştir (Tablo 2). Aynı zamanda çocukların düşük ağırlıklı olma endişesi artıkça annelerin baskı düzeyinin arttığı; çocukların fazla kilolu olma endişesi arttıkça ise besin sınırlama düzeyinin arttığ saptanmıştır. Annelerin çocuklarına yeme baskısı artıkça da çocuk daha seçici olmaktadır. Her iki yönlü baskının çocukların sağlıklı yeme davranışını olumsuz yönde etkileyebileceği göz önünde bulundurulmalıdır. Yeme baskısı yaşayan çocuklarda ilerleyen yaşlarda yeme bozukluklarının daha sık görüldüğü saptanmıştır. Anneler çocuklarına baskı yapmaktan kaçınmalıdır.

Ebeveynlerin belirli gıdaları teşvik etmek ya da ondan vazgeçirmek için kullandığı yöntemler bazen istedikleri şekilde sonuçlanmamaktadır. Genelde çocuklar kendilerine verilmek istenmeyen besinleri daha çok yeme, yemesini istedikleri besinleri ise yememe eğilimindedir [22]. Yapılan bir çalışmada, çocuklara çeşitli öğünler sunulmuş ve bir gruba yemesi için baskı yapılmış, diğer gruba ise yapılmamıştır. Baskı yapılan çocukların daha fazla yemek yediği ancak baskı yapılan besinleri baskı yapılmayanlara oranla daha az miktarda tükettikleri görülmüştür [23]. Yeme baskısı anneler üzerinde yapılan çalışmalarda düşük BKİ (Beden Kütle İndeksi) ile ilişkilendirilmiştir [24 ve 25]. Diğer bir başka çalışmada düşük gelirli Afro-Amerikan ve okul öncesi çocuğu olan annelerin çocuklarının yemeklerini kontrol etme durumu ve çocukların BKİ'leri arasındaki ilişki araştırılmıştır. Çalışma sonuçlarına göre yeme baskısı ile çocuğun BKİ'si arasında anlamlı bir ilişki olduğu bulunmuş ve düşük BKİ'ye sahip çocukların annelerinin yemek yemeleri için daha fazla 


\section{Nevşehir Bilim ve Teknoloji Dergisi (2018), 7(1) 1-13}

baskı yaptığı belirlenmiştir [26]. Nowicka ve arkadaşlarının (2014) yaptıkları çalışmanın sonucuna göre çocuğun BKI’si yeme baskısıyla negatif ilişkili sınırlama ile pozitif ilişkili bulunmuştur [27]. Benzer çalışmada ebeveynlerin çocuklarının BKİ'leri arttıkça sınırlayıcı yeme davranışlarının arttığı görülmüştür [19]. Hollanda'da 4987 çocuğun katıldığı bir kohort çalışmasında da çocuğun BKİ'si duygusal olarak az yemesi, memnuniyeti ve seçiciliği ile yeme baskısı negatif ilişkili bulunmuştur [28]. Başka bir çalışmada ise BKI'si ile annelerin yeme baskısı negatif ilişkili iken, izlem ve kısıtlama ile pozitif ilişkili bulunmuştur [16].

Annelerin büyük çoğunluğu çocuklarının fazla şekerli (\%97.2) ve yağlı (\%97.6) besinleri gereğinden çok yemediğinden emin olmak istediklerini belirtmişlerdir. Annelerin çocuğunun yaptığı iyi davranışa ödül olarak ona kek, pasta, çikolata vb. şekerli besinlerin verilmesine katılanların oranı sadece \% 7.1'dir. Annelerin \%23.9’u çocuk aç değilse, yemek yedirmeye uğraşmadıklarını ifade etmişlerdir. Ayrıca kontrol ve rehberlik etmediklerinde çocuklarının yemesi gerekenden daha az miktarda besin tükettiği ile ilgili düşünceleri konusunda kafalarının karışık olduğu söylenebilir (Tablo 2).

Çocukların duygu durumları da beslenmelerini etkilemektedir. Çocuğun üzüntülü, kaygılı olması ya da hasta olması yeme düzenini etkilemezken, mutlu olduğunda daha fazla yemek yemektedir. Duygu durumların göre de çocukların iştah durumlarında ve yemeği hızlı tüketmesinde değişmeler olmaktadır. Genel olarak çocuklar kolaylıkla doymaktadır. Çocuklar izin verildiği durumlarda bile bir şeyler yiyip içmemektedir.

Çalışma sonuçları incelendiğinde annelerin çocuklarının beslenmelerini kontrol ettikleri görülmektedir. Bu durum annelerin yeterli beslenme bilgisine sahip olmaları ve bu bilgileri doğru şekilde çocuklarına aktarabilmeleri gerçeğini ortaya çıkarmaktadır. Jennings ve arkadaşlarının (2011) çalışmalarında da okul öncesi çocuğu olan ebeveynlerin çocuk beslenmesi konusunda eğitilmesi ve aynı zamanda bu kurumlarda çocuklara uygun süt, sağlıklı içecek, atıştırmalık ve yiyecek temin edilerek, sağlıklı beslenme alışkanlıklarının oluşturulmasının sağlanmasının gerekliliği ifade edilmiştir [29]. Konya'da yürütülen önceki bir araştırmada da çocukların düzenli kahvaltı yapma durumlarıyla ebeveynlerinin beslenme bilgi puan ortalamaları arasında ortaya çıkan farklılıklar önemli $(\mathrm{p}<0.05)$ bulunmuştur [30].

Yapılan bir gözlemsel çalışmada ev ortamında ebeveynlerin zamanlarının çoğunda çocuklarına istediklerini sormaksızın besin sunduğu gösterilmiştir. Ebeveynlerin, \%85.0’i çocuklarının daha fazla yemesi için uğraşmaktadır [31]. Bu çalışmada da genel olarak annelerin çocuklarının yeme davranışlarını kontrol etmeye çalıştıkları saptanmıştır. Anneler çocuk yemek yerken yanında bulunmaları gerektiğini, kontrol etmezlerse çocuğun gereğinden daha az ya da daha çok yiyeceğini düşünmektedir. Anneler çocukları yemek yerken çocuğa çok fazla uyarı yapmamalı ve ısrarda bulunmamalıdır. Ebeveynler baskı kurarak çocuklarına doygunluk noktasına ulaşmasını ve tokluk sinyallerini fark edememelerine yol açabilirler. Bir çalışmada, çeşitli sosyoekonomik ve etnik kökenden gelen annelerin çocuklarının tok olduğunu söylediği zaman onlara inanmadıkları bildirilmiştir [32]. Bu da annelerin daha fazla yemeleri için baskı kurmasına ve çocuklarının doyma sınırlarını aşmasına sebep olabilmektedir. Yeme davranışları obezite gelişiminde belirleyici bir faktör olarak görülmektedir. Yapılan bir araştırmada çocukluk obezitesi, besinden keyif alma, duygusal aşırı yeme ve besin heveslisi gibi iştah göstergeleri ile pozitif ilişkili bulunurken; yavaş yeme ve tokluk heveslisi (yeme isteksizliği) gibi iştahsızlık göstergeleri ile negatif ilişkili bulunmuştur [33]. Obezite günümüzde önemli bir sağlık sorunu olarak görülmektedir. Aynı zamanda yol açtığı birçok kronik hastalık itibariyle de yaşam kalitesini ve süresini tehdit etmektedir. Sadece bu konu bile annelerin çocuk beslemesi uygulamalarının önemini ortaya koymaktadır.

Çocukluk döneminde yeme konusunda baskıcı ailelerin çocuklarında yeme bozuklukları daha sık olarak görülmekte ve çocuk daha seçici olmaktadır [34 ve 35]. Bu nedenle ailelerin bu konuda dikkatli olmaları ve çocuklarına baskı yapmaktan kaçınmaları gerekmektedir. Çocuklar yeme konusunda bağımsız davranabilecek şekilde yetiştirilmelidir. Ancak bu durum gerçekleştirilirken çocukların sağlıklı seçimler yapabilmesi için gerekli beslenme bilgisinin doğru 
şekilde verilmesi de önemlidir. Annelerin bu konudaki bilgileri çocuklarının beslenmesini etkilemektedir ve annelerin doğru beslenme uygulamalarını bilmeleri bu açısından önem kazanmaktadır.

5. Kaynaklar

[1] Merdol T. K., “Okul Öncesi Dönem Çocukları Beslenmesi”, T.C. Sağlık Bakanlığı Yayınları, Ankara, 2008

[2] Kırkıncıŏlu M., “Çocuk Beslenmesi” Ya-Pa Yayınları, İstanbul, 2003

[3] Yalvaç S., Erkan T., Erginöz E., Çokuğraş F. Ç., Kutlu T., "Bahçelievler çocuk yuvası 0-6 yaş grubunda beslenme durumunun değerlendirilmesi”, Türk Pediatri Arşivi, 43, 89-93, 2008

[4] Arlı M., Şanlıer N., Küçükkömürler S., Yaman M., “Anne ve çocuk beslenmesi” Pegem Akademi Yayınları, Ankara, 2012

[5] Bryant-Waugh R., Markham L., Kreipe R. E., Walsh, B. T., "Feeding and eating disorders in childhood" International Journal of Eating Disorders, 43, 98-111, 2010

[6] Selimoğlu M. A., "Sağlıkta ve Hastalıkta Çocuk Beslenmesi”, Akademi Yayınları, İstanbul, 2014

[7] Erkan T., Yalvaç S., Erginöz, Çokuğraş F. Ç., Kutlu T., “İstanbul Üniversitesi Cerrahpaşa Tıp Fakültesi Çocuk Yuvası'ndaki çocukların beslenme durumlarının antropometrik ölçümlerle değerlendirilmesi”, Türk Pediatri Dergisi, 42, 142-147, 2007

[8] Birch L. L., Fisher J. O., Grimm-Thomas K., Markey C. N., Sawyer R., Johnson S. L., “Confirmatory factor analysis of the Child Feeding Questionnaire: a measure of parental attitudes, beliefs and practices about child feeding and obesity proneness”, Appetite, 36, 201-210, 2001

[9] Camc1 N., Bas M., Buyukkaragoz A. H., "The psychometric properties of the Child Feeding Questionnaire (CFQ) in Turkey”. Appetite, 78, 49-54, 2014

[10] Wardle J., Guthrie C. A., Sanderson S., Rapoport L., "Development of the Children's Eating Behaviour Questionnaire”, Journal of Child Psychology and Psychiatry, 42, 963-970, 2001

[11] Yılmaz R., Esmeray H., Erkorkmaz Ü., “Adaptation study of the Turkish children's eating behavior questionnaire”, Anatolian Journal of Psychiatry, 12, 287-294, 2011

[12] Lloyd-Williams F., Bristow K., Capewell S., Mwatsama M., "Young children's food in Liverpool day-care settings: a qualitative study of pre-school nutrition policy and practice”, Public Health Nutrition, 14, 18581866, 2011

[13] Hu C., Ye D., Li Y., Huang Y., Li L., Gao Y., Wang, S., "Evaluation of a kindergarten-based nutrition education intervention for pre-school children in China”, Public Health Nutrition, 13, 253-260, 2010

[14] Schmidt R., Richter R., Brauhardt A., Hiemisch A., Kiess W., Hilbert A., "Parental feeding practices in families with children aged 2-13 years: Psychometric properties and child age-specific norms of the German version of the Child Feeding Questionnaire (CFQ)”, Appetite, 109, 154-164, 2017

[15] Cachelin F. M., Thompson D., "Predictors of maternal child-feeding practices in an ethnically diverse sample and the relationship to child obesity”, Obesity, 21, 1676-1683, 2013

[16] Canals-Sans J., Blanco-Gómez A., Luque V., Ferré N., Ferrando P. J., Gispert-Llauradó M., Esc ribano J., Closa-Monasterolo R., "Validation of the child feeding questionnaire in spanish parents of school children”, Journal of Nutrition Education and Behavior, 48, 383-391, 2016 
[17] Yavuz H. M., Selçuk B., "Predictors of obesity and overweight in preschoolers: The role of parenting styles and feeding practices” Appetite, 120, 491-499, 2018

[18] Gregory J. E., Paxton S. J., Brozovic A. M., "Pressure to eat and restriction are associated with child eating behaviours and maternal concern about child weight, but not child body mass index, in 2-to 4-year-old children”, Appetite, 54, 550-556, 2010

[19] Ainuki T., Akamatsu R., “Associations Between Children's Appetite Patterns and Maternal Feeding Practices”, Food and Nutrition Sciences, 2, 228-234, 2011

[20] Jani R., Mallan K. M., Daniels L., “Association between Australian-Indian mothers' controlling feeding practices and children's appetite traits”, Appetite, 84, 188-195, 2015

[21] Ek A., Sorjonen K., Eli K., Lindberg L., Nyman J., Marcus C., Nowicka P., “Associations between Parental Concerns about Preschoolers' Weight and Eating and Parental Feeding Practices: Results from Analyses of the Child Eating Behavior Questionnaire, the Child Feeding Questionnaire, and the Lifestyle Behavior Checklist”, PloS one, 11s, 2016

[22] Birch L. L., Fisher J. O., “Development of eating behaviors among children and adolescents”, Pediatrics, 101, 539-549, 1998

[23] Galloway A. T., Fiorito L. M., Francis L. A., Birch, L. L., “'Finish your soup': Counterproductive effects of pressuring children to eat on intake and affect” Appetite, 46, 318-323, 2006

[24] Francis L. A., Hofer S. M., Birch, L. L., "Predictors of maternal child-feeding style: Maternal and child characteristics”, Appetite, 37, 224-231, 2001

[25] May A. L., Donohue M., Scanlon K. S., Sherry B., Dalenius K., Faulkner P., Birch L. L., “Child-feeding strategies are associated with maternal concern about children becoming overweight, but not children's weight status”, Journal of the American Dietetic Association, 107, 1167-1174, 2007

[26] Powers S. W., Chamberlin L. A., Schaick K. B., Sherman S. N., Whitaker R. C., "Maternal feeding strategies, child eating behaviors, and child BMI in low-income African-American preschoolers", Obesity, 14, 2026-2033, 2006

[27] Nowicka P., Sorjonen K., Pietrobelli A., Flodmark C. E., Faith M. S., "Parental feeding practices and associations with child weight status: Swedish validation of the Child Feeding Questionnaire finds parents of 4-year-olds less restrictive”, Appetite, 81, 232-241, 2014

[28] Jansen P. W., Roza S. J., Jaddoe V. W., Mackenbach J. D., Raat H., Hofman A., Verhulst F. C., Tiemeier H., "Children's eating behavior, feeding practices of parents and weight problems in early childhood: results from the population-based Generation R Study”, International Journal of Behavioral Nutrition and Physical Activity, 9, 130, 2012

[29] Jennings A., Mc Evoy S., Corish C., "Nutritional practices in full-day-care pre-schools", Journal of Human Nutrition and Dietetics, 24, 245-259, 2011

[30] Cebirbay M. A., Aktaş N., “Okulöncesi Kurumlara Devam Eden 4-6 Yaş Grubu Çocukların Kahvaltı Alışkanlıkları ve Ebeveynlerinin Beslenme Bilgilerinin Belirlenmesi”, Hacettepe Üniversitesi Săğlk Bilimleri Fakültesi Dergisi, 1, 1-11, 2016

[31] Orrell-Valente J. K., Hill L. G., Brechwald W. A., Dodge K. A., Pettit G. S., Bates J. E., “Just three more bites": An observational analysis of parents' socialization of children's eating at mealtime”, Appetite, 48, 37-45, 2007

[32] Sherry B., Mc Divitt J., Birch L. L., Cooks F. H., Sanders S., Prish J. L., Francis L. A., Scanlon K. S., “Attitudes, practices, and concerns about child feding and child weight status among socioeconomically diverse white, Hispanic, and African-American mothers”, Journal of the American Dietetic Association, 104, 215-221, 2004 
[33] Santos J. L., Ho-Urriola J. A., González A., Smalley S. V., Domínguez-Vásquez P., Cataldo R., Obregon A. M., Amador P., Weisstaub G., Hodgson M. I., “Association between eating behavior scores and obesity in Chilean children”, Nutrition journal, 10, 108, 2011

[34] Aktaş N., “Okul Çağı Çocuklarının Beslenme Alışkanlıkları: Ebeveyn ve Okulun Rolü”, Editör: Aral N., Üniversitesi Sağlık Bilimleri Fakültesi Yayınları, Ankara, 257-266, 2012

[35] Swyden K., Sisson S. B., Morris A. S., Lora K., Weedn A. E., Copeland K. A., DeGrace B., “Association between maternal stress, work status, concern about child weight, and restrictive feeding practices in preschool children” Maternal and Child Health Journal, 21, 1349-1357, 2017 
Nevşehir Bilim ve Teknoloji Dergisi (2018), 7(1) 1-13

\section{Extended Abstract}

\section{Introduction}

The pre-school period is the period from birth to the age of 6, including gaining many habits. For this reason, it is important to acquire healthy eating habits in this period. On the other hand, the examination of the factors influencing nutrition behavior in this period is gaining importance when the prevalence of childhood obesity is taken into consideration. In this period, children's eating behaviors are affected by various factors and the positive eating habits that have been earned continue to be advanced. This situation can determine whether some children are overweight or have eating disorders compared to others. In this context, in this research, it is aimed to evaluate the nutrition practices and eating behaviors of the pre-school-age children.

\section{Method}

The research population consisted of five kindergartens located in Ankara province and the sample was mothers with children aged 2-6 who attend these kindergartens. 400 mothers were planned to participate this cross-sectional study; although 255 mothers participated due to various reasons. Data was collected face-to-face. The questionnaire includes general information about the mother and the child, as well as questions about the mother's nutrition practices, childhood obesity tendencies and eating behavior of children. Mothers' child nutrition practices were determined using the Child Feeding Questionnaire (CFQ) scale developed by Birch et al. (2001), Turkish validity and reliability by Camci et al. (2014). This scale includes 21 expressions and is a measure for determining the mother's nutrition attitudes and practices. The scale consists of perceived responsibility, monitoring, attention to child weight, restriction and eating pressure subscales. Eating behavior of children was assessed using Turkish children's eating behavior questionnaire by Y1lmaz et al. (2011). This scale includes 35 expressions and is a measure for determining child's nutritional approach and abstinence behaviors. Scale consists of nutrition eager, emotional overeating, nutritional enjoyment, drinking passion, satiety eagerness, slow eating, emotional under eating and nutrient selection subscales. The data obtained as a result of the research were evaluated by using the SPSS statistical program.

\section{Results and Discussion}

$47.8 \%$ of the children were girls and $52.2 \%$ were boys. The majority of children (78.8\%) were over 3 years old. $17.6 \%$ of the mothers assessed their child as overweight in $0-1$ years old, $11.8 \%$ of the mothers assessed their child as slim in the $2-3$ years, $12.9 \%$ of the mothers assessed their child as slim in $3-4$ years, and $12.2 \%$ of the mothers assessed their child as slim in 5 years and over. 50.2\% of the mothers thought theirself responsible for their children's right food choices and they control their childrens' sugary food (78.4\%), junk food (75.3\%) and fat-rich foods (78.4\%) consumption. It was determined that $29.4 \%$ of the mothers were concerned about their children's body weights. $34.9 \%$ of the mothers thought that sometimes their children like to eat, $49.0 \%$ thought that their children leave food on the plate, $38.0 \%$ of the mothers thought that their children enjoy new food, while $42.4 \%$ of the mothers thought that their children reject new food, 35.3\% thought sometimes it is hard to make children happy with food. 68.6\% of the mothers want to be sure that their children do not eat too much sugary foods (ice cream, sugar, cake), $67.8 \%$ of the mothers want to be sure that their children do not eat fatty foods. When the subscale total scores were examined at both scales, no significant difference was found between genders ( $\mathrm{p}>0.05)$. Mothers' eating pressure showed negative correlation with children's nutritional enjoyment behaviour $(\mathrm{R}=$-. 230, $\mathrm{p}<0.01)$ and positive correlation with nutrient selectivity $(\mathrm{r}=-.196, \mathrm{p}<0.01)$, satiety eagerness $(\mathrm{r}=.363$, $\mathrm{p}$ $<0.05)$, slow eating behavior $(r=.243$; $p<0.01)$. Mothers' restriction with eating pressure $(r=.306 ; p<0.01)$ and the interest about child's weight $(r=.383$; $\mathrm{p}<0.05)$ correlated positively. As a result of this study, it has been observed that the mothers have a repressive attitude about the nutrition of their children. This can cause children to exhibit eating behaviors that may be more prone to nutritional problems and, consequently, obesity. For this reason, it is necessary for mothers to avoid repressive and restrictive behaviors in order to gain their children right eating habits and to make healthy choices. 